\title{
How Does Preschoolers' Conformity Relate to Parental Style, Anonymous Sharing, and Obedience?
}

\author{
Kahl Hellmer*, Gunilla Stenberg and Christine Fawcett \\ Department of Psychology, Uppsala University, Uppsala, Sweden
}

\begin{abstract}
Children, just like adults, conform to peer testimony when making ostensibly easy decisions. Yet, some are more prone to conform than others and little is known about which factors contribute to this variability. In the current study, we aimed to investigate the reasons for individual differences in conformity by examining potential correlates of experimentally-elicited conformity in a sample of Swedish 3.5-year-olds $(N=55 ; 56 \%$ girls). Specifically, we asked whether conformity was socialized by parents via their parental style and whether conformity is correlated with the behaviors of anonymous sharing or obedience, which might each share a common motivation with conformity. Our data showed that children's conformity was associated with fathers', but not mothers', authoritarian parental style and with anonymous sharing, but not obedience. The findings lend support to the notions that authoritarian parental style encourages conformist behavior, and that conformity is correlated with anonymous sharing behavior.
\end{abstract}

\section{Keywords}

Conformity, obedience, anonymous sharing, authoritarian parental style

A plethora of evidence shows that most adults, to some extent, conform to majority testimony in laboratory settings, even when their doing so is seemingly incompatible with their perceptual information (e.g., Asch, 1956; Bond \& Smith, 1996). Using easily discriminable stimuli in a setting purported to be a perception experiment, conformity is operationalized as answering in agreement with an incorrect majority. Children are not exempt from such behavior and several principal findings from the adult conformity literature have been replicated with children -

\footnotetext{
*Address for correspondence

Kahl Hellmer, Department of Psychology, Uppsala University, Box 256, 75105 Uppsala, Sweden. E-mail: kahl.hellmer@psyk.uu.se
}

showing that conformity prevalence rates are similar from as young as three years of age to adulthood (e.g., Corriveau \& Harris, 2010; Flynn, Turner, \& Giraldeau, 2018; Haun \& Tomasello, 2011; Berenda, 1950; Haun, Rekers, \& Tomasello, 2012; Walker \& Andrade, 1996).

Conformity, while ostensibly a simple copying of another person, is in fact a complex social-cognitive behaviour and it has been proposed to be an intrinsic component of children's social learning (Whiten \& Flynn, 2010) and vital to human development (McGuigan \& Robertson, 2015). Firstly, from a normative perspective, conformity can be used as a strategic social behavior to strengthen affiliation with others already from preschool age. For example, 
nearly 50 percent of 5-year-olds conform to peers even when they act immorally (Engelmann et al., 2016) and 3-year-old observer children also expect third-party ostracized peers to conform as a means of affiliation (Cordonier et al., 2017). Secondly, from an informational perspective, conformity can stem from a desire to report correct information, and selecting whose testimony or behavior to potentially imitate in order to arrive at the correct response is shaped over time via learning mechanisms (Klucharev et al., 2009) considering both ambiguity of testimonials and trust in those who give them (Morgan et al., 2015). Although young children copy task-irrelevant behavior from adults, they are able to forego such behavior when it is displayed by peers (McGuigan $\&$ Stevenson, 2016) or younger children (McGuigan $\&$ Burgess, 2017). Likewise, children's propensity to conformity drops significantly if they are given a sense of expertise or prior knowledge (SebastiánEnesco et al., 2020; Schillaci \& Kelemen, 2014) or if models are portrayed as incompetent (Eagly \& Wood, 1982).

Taken together, studies on developmental conformity have unveiled that young children demonstrate complex socio-cognitive processing, yet there has been little effort to examine why there is variability in the propensity to conform. Recent work suggests moderate longitudinal stability in social learning strategies indicating that up to 40 percent of inter-individual variability pertains to individual differences rather than measurement errors or situational factors (Juteau et al., 2019). Addressing this variability from another perspective, children's propensity to conform correlates with their parents' extraversion (Hellmer et al., 2018). Moreover, cross-cultural work shows that adults value children's conformity differently both within and across cultures (Clegg et al., 2017) plausibly indicating that parents differ in their reinforcement of conforming behavior. The primary aim of the current study is to investigate if preschoolers' propensity to conform is socialized by parents via parental style, a central psychosocial element in determining children's relationship with the social world. A secondary aim is to gain insight on the motivations behind conformity by assessing whether it correlates with behaviors that could have similar motivations: obedience and anonymous sharing. Showing that children's conformity is potentially correlated with parental style other social behaviors adds to our understanding of the early ontogenetic roots of a behavior that is key to our social worlds, friendships, and learning.

\section{Parental Style}

Parental style is a characterization of strategies and behaviors in the socialization practices of child rearing. These practices are dependent on parents' personality, attitudes, and ideologies, but also markedly affected by transactional effects in the parent-child dyadic relationship (Clark et al., 2000; Pastorelli et al., 2016; Prinzie et al., 2009; Zadeh et al., 2010). Importantly, multiple lines of evidence show that parental style has effects on children's social behavior. Examples include externalizing behavior (e.g., Pinquart, 2017), peer play (Gagnon et al., 2014), and children's trust in adults who act unconventionally (Reifen Tagar et al., 2014).

In the current work, we focus on three parenting styles: authoritative, authoritarian, and permissive (Robinson et al., 1995). These styles were factored out from the theoretical framework developed by Baumrind (1968) where the two dimensions of demandingness and responsiveness were originally delineated. The authoritative style is demanding and responsive, the authoritarian style is demanding but non-responsive, while the permissive style is responsive but non-demanding. Out of the three, only the authoritarian parenting style has specifically been argued to encourage conformity (Berger, 2014). The rationale behind this argument builds on the notion the authoritarian personality trait (see e.g., Baars \& Scheepers, 1993; Stenner, 2009) or right-wing authoritarianism is intrinsically related to conforming and acquiescing to social norms (e.g., Vaughan \& White, 1964) and links between parental right-wing authoritarianism and children's rates of conformity have been shown (Guidetti et al., 2017). Right-wing authoritarianism, in turn, correlates moderately with authoritarian parenting style (Manuel, 2006). Moreover, it has been shown that fathers' self-reported parental style is more related than that of mothers to children's behavioral outcomes (Roopnarine et al., 2006; Tavassolie et al., 2016). In the current study we therefore keep parents' ratings of their own parental style separated. Additionally, we allow parents to rate each other's parental style to obtain a more reliable measurement. Our overall hypothesis is that authoritarian parenting style will predict children's likelihood of conforming to peers.

\section{Obedience}

Obedience is behaving in line with the demands of an authority figure. It is conceptually similar to 
conformity in that both entail a change in behavior reflecting individuals' acquiescence to instructions or expectations. However, obedience occurs in response to direct requests from authority figures and conformity to the influence that a majority of others exerts. Thus, when experimentally eliciting conformity, careful attention has to be paid to obedience because it is a behavior with a potentially related motivation: to do what others expect of you. If participants conform to an adult majority portrayed as competent while being instructed by an experimenter to produce correct results, an answer that is conformist may be motivated by obedience to authority (e.g., Ma \& Ganea, 2010). In the current study, we therefore rely on peer confederates to provide the majority testimony. Moreover, obedience is also conceptually similar to instrumental helping in which the helper assists in achieving an action-based goal. The difference is that obedience is initiated by an authority figure and is motivated by avoiding negative external consequences rather than obtaining positive internal rewards. Here, we examine if there is a linkage between conformity and an experimentally acquired measure of obedience to an adult figure, as a way of determining whether they are based on common motivations to defer to others' authority.

\section{Anonymous Sharing}

In contrast to a motivation to defer to authority, conformity can also be driven by a desire to affiliate (social alignment system; Shamay-Tsoory et al., 2019), which can be interpreted as a prosocial motive (Cirelli, 2018). For example, 5-year-olds' sharing behavior is related to earlier experiences of social interactions (Paulus \& Leitherer, 2017). To our knowledge, potential covariance between conformity and sharing behavior has not yet been investigated. In an oft-employed method to assess anonymous sharing, the participant is given a resource and an opportunity to share this resource with an unknown receiving participant. Importantly, participants believe that experimenters are blind to their sharing, meaning that they do not expect to receive recognition for their action and any sharing is only motivated by a desire to benefit another person.

Previous studies have linked conceptually similar sharing with theory of mind (Takagishi et al., 2010), moral emotions (Gummerum et al., 2010), attachment security (Paulus et al., 2016), and the honesty-humility trait dimension from the
HEXACO-model of personality (Allgaier et al., 2020). Here, we chose to examine whether there was an association between anonymous sharing and conformity. That is, are children with a larger propensity to conform also more prone to anonymously share their resources? Such a correlation would be theoretically relevant and imply common underlying prosocial motivation for the two behaviors. The current work was part of a larger preregistered study which investigated various correlates of conformity, some of which are not included in the current work (https://osf.io/eq3cw). For the current study, we hypothesized that conformity correlates positively with obedience, that sharing is associated with both conformity and obedience, and that conformity is associated with authoritarian parental style. The other part of the preregistered study pertains to children's personality and motivation to conform (Hellmer et al., 2021).

\section{Method}

\section{Participants}

Participants were a sample of 55 3.5-year-olds (31 girls, 24 boys; $M=42$ months, 3 days; $S D=31$ days; range [39 months, 30 days; 43 months, 31 days]) recruited from Uppsala, a medium-sized city in Sweden. Information about ethnicity and SES was not collected, but participating parents were primarily native Swedes with university education. Parents of all participants gave informed consent prior to participation. Four additional participants were tested in the lab but were excluded due to difficulties understanding the task (e.g., explicitly stating a strategy of pointing to random targets and ostensibly perpetuating this throughout the experiment). The procedures used in the study were approved by Uppsala Regional Ethics Committee (Dnr 2015/021; 'The development of social imitation and conformity').

\section{Materials}

Questionnaire. The Parenting Styles and Dimensions Questionnaire (PSDQ, $N$ items = 33; Robinson et al., 1995) was used to measure parental style. All items of the PSDQ were phrased so that each parent gave one rating of their own parental style and one rating of the other parent's parental style and were rated using the alternatives never, once in a while, about half of the times, very often, and always. The PSDQ includes 


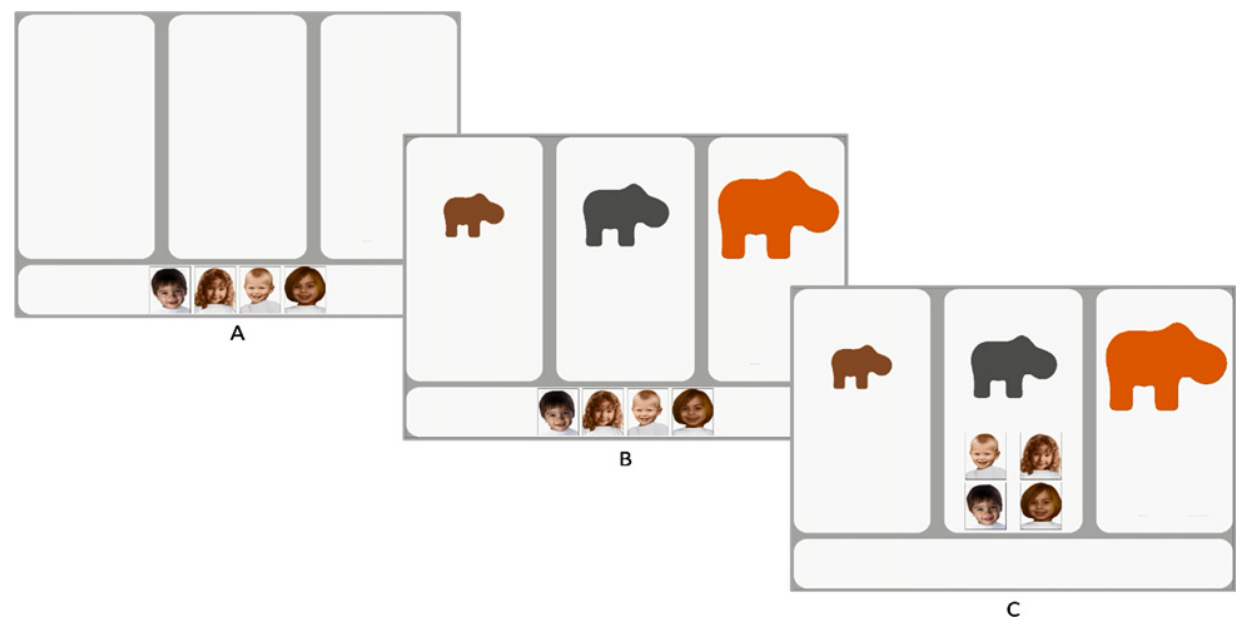

Figure 1. Images to illustrate an incongruent trial. (A) Each trial starts with the four peers depicted in the screen's lower area. (B) After 2 $\mathrm{s}$ the targets appear, accompanied by a clicking sound. After another $3 \mathrm{~s}$ the peers start moving, one-by-one to a unanimous target, each individually stating "this one". (C) With all of the peers" choices indicated, the Experimenter asks the participant for their explicit choice.

items to assess authoritarian (e.g., scold and criticize to make our child improve; use threats as punishment with little or no justification), authoritative (explain the consequences of the child's behavior; responsive to our child's feelings and needs), and permissive parenting practices (find it difficult to discipline our child; spoil our child).

Experimental Tasks. For the conformity task, we used video stimuli as shown in Fig. 1. Each trial began with the four peer children's photographs at the bottom of the screen. Next, three animals with different colors appeared above the peers (colors and positions of targets were counterbalanced). After five seconds, the peers moved one-by-one (order of peer movements were counterbalanced) to one of the animals; with audio for each peer stating "this one". From here, the screen was frozen to allow for an explicit answer from the participant. After four familiarization trials in which peers unanimously chose the correct target, peers unanimously chose the middle-sized target on 50 percent of trials and chose the correct target on the remaining trials. Video stimuli can be found at https://osf.io/tn436/.

Additionally, a paper cup with 20 plastic paperclips of various colors was used in the obedience task and plastic bags with 10 glass marbles were used in the anonymous sharing task. There were no video recordings of participants' behavior in the obedience or the anonymous sharing tasks and outcomes of each task were noted by the Experimenter during the session.

\section{Procedure}

Questionnaires. Parents were instructed to complete the PSDQ before visiting the lab. Seven parents completed the questionnaire after the visit but were still included in analyses. Parents also completed questionnaires on their own and their child's personality which are not part of the current study.

Conformity. Participants were welcomed into the lab by the Experimenter, a male in his late thirties. The Experimenter told the participant that he had heard that the participant was very good at seeing which of similar things were the largest and invited them to help out by playing a game. The Experimenter told the participant that there were four other same-aged children that were co-participating from other rooms in the same building. Prior to the experiment's start, participants had a pre-test with two example stimuli similar to those used in the experiment, but viewed on paper instead of on-screen. The pre-test allowed the Experimenter to make clear that he could not tell the difference between the three targets and thus needed help with it during the task, as well as serving as a screening to ensure each participant's ability to discriminate the largest target prior to participation in the experiment. All participants passed the pre-test by answering correctly on both trials.

Participants were seated in front of a Tobii T120 eye-tracker which was used to display the video stimuli. Eye tracking data was collected but is not analyzed in the current study. Parents were sitting 
clearly visible to the participants, but in a location where the participant could tell that they could not see their screen. This was to give the participant a sense of anonymity to the Experimenter and the parent, but not to their co-participating peers. Before the four familiarization trials, participants were told that the four peers were also ready to start the experiment and that the participant was supposed to give their answer last. This was clarified to each participant as even though they could immediately see which animal is the largest, they would have to refrain from responding until the Experimenter asked them to identify their answer.

When the peers had made their choice, the Experimenter repeated to the participant that "all the other children chose the [color of the chosen target] [animal] - which [animal] do you think is the largest?" Participants could verbally or gesturally choose a target and the experimenter confirmed the answer informally, "so you (also) think the [color of the chosen target] is the largest" and made a note. After each trial, the Experimenter stated clearly that the participant's answer was made clear to the four peers. On all occasions where the participant's answer was identical to the peers', the Experimenter stated "Now, the other children can see that you also chose the [chosen target t". On all occasions where the participants' answer differed from the peers', the Experimenter stated "Now, the other children can see that you chose the [chosen target] instead". A total of eight congruent (peers chose the correct target) and eight incongruent trials (peers chose the incorrect target) were included the experiment, following the four (congruent) familiarization trials.

Obedience. The Experimenter pretended to accidentally spill a paper cup containing 20 plastic paper-clips onto the floor near the participant. The Experimenter firmly instructed the participant that "you will have to pick those up, I don't have time because I have to look at important papers with your parent". The Experimenter quickly turned their back to the participant and reminded the parent to also do this while pretending to attend some papers. After 60 seconds, the Experimenter turned back to the participant and excused their behavior "I'm sorry for telling you to pick up my paper-clips. I was the one who spilled them and I should have picked them up." While this task was inspired by tasks designed to elicit helping (e.g., Warneken, 2015), several key differences make it more likely to elicit obedience than helping: the experimenter gives a direct order, he does not remain engaged with the task or the child, and he is clearly capable of completing the task himself (Landauer et al., 1970).

Anonymous Sharing. The Experimenter stated that he remembered that there is a gift for the participant in a cardboard box placed on the floor in the room. The Experimenter and the participant sat down by the box and lifted the lid open. The box contained one transparent plastic bag holding ten glass marbles. The Experimenter picked the bag up and stated "These are glass marbles. You can play with them, roll them, or you can just look at them because they're beautiful. I want you to have these" and then gave the bag to the participant before again stating that "now they are yours".

Immediately after the participant turned to walk away from the Experimenter, the Experimenter said "Oh no! That was really stupid of me" and asked the participant to stand next to them: "These are your marbles; I gave them to you. But I just remembered that in a few minutes there is another child, who is exactly as old as you are, who is going to participate in the same game. But those were my last marbles so I cannot give that child any marbles". The experimenter then repeatedly informed the child that "These are your marbles and you are free to keep them all, but if you want to, you can place some of your marbles for the next child-but you don't have to. Your parent and I have to attend some important papers and will have our backs turned to you so no one will see or know if you share your marbles or not". When the participant expressed that they were done, the Experimenter and parent turned to the participant again.

\section{Data Coding}

The conformity experiment provided data from two within-subjects conditions: congruent (peers chose the correct target) and incongruent (peers chose the incorrect target). Data from the congruent trials was used only as a manipulation check to ensure that participants as a group altered their responding based on the peers' responses. Analyses of conformity propensity are based on data from incongruent trials only and are coded from participants' explicit answer in each trial. Conforming responses were those in which a participant incorrectly identified the middle-sized animal in line with peers and these were converted to a scalar conformity score for each participant ranging between 0.0 and $1.0(0=$ not conforming on any trial; $1=$ conforming on every trial). Behavioral tasks were coded by the experimenter during or directly after the session. Obedience was coded as 
Table 1

Summarization of the PSDQ (Robinson, Mandleco, Olsen, \& Hart, 1995) Showing Mean (M), Within-Factor Standard Deviation (SD), and Inter-Item Reliability $(\alpha)$ by Parent Gender; Correlations (Pearson's $r$ ) and Inter-Rater Reliability (Cohen's kappa; $\kappa$ ) by Parent Ratings

\begin{tabular}{|c|c|c|c|c|c|c|c|c|c|}
\hline & & \multicolumn{3}{|c|}{ Self-rated } & \multicolumn{3}{|c|}{$\begin{array}{c}\text { Rated by other } \\
\text { parent }\end{array}$} & \multirow[b]{2}{*}{$r$} & \multirow[b]{2}{*}{$\kappa$} \\
\hline & & $M$ & $S D$ & $\alpha$ & $M$ & $S D$ & $\alpha$ & & \\
\hline \multirow[t]{2}{*}{ Authoritarian } & Mother & 1.56 & 0.36 & 0.76 & 1.53 & 0.30 & 0.65 & $0.49^{* *}$ & $0.48^{* *}$ \\
\hline & Father & 1.59 & 0.25 & 0.58 & 1.51 & 0.34 & 0.72 & $0.40^{* *}$ & $0.36^{* *}$ \\
\hline \multirow[t]{2}{*}{ Authoritative } & Mother & 3.79 & 0.46 & 0.79 & 3.69 & 0.50 & 0.85 & 0.18 & 0.18 \\
\hline & Father & 3.62 & 0.52 & 0.89 & 3.69 & 0.52 & 0.82 & 0.23 & 0.22 \\
\hline \multirow[t]{2}{*}{ Permissive } & Mother & 2.08 & 0.42 & 0.61 & 2.05 & 0.32 & 0.49 & $0.48^{* *}$ & $0.42^{* *}$ \\
\hline & Father & 2.00 & 0.31 & 0.34 & 2.02 & 0.41 & 0.60 & $0.33^{*}$ & $0.32^{*}$ \\
\hline
\end{tabular}

1 if the paper clips spilled by the experimenter were picked up, and 0 if not. No participants picked up only some of the clips. Anonymous sharing was coded from 0-10 in accordance with the number of marbles shared. The PSDQ was computed according to instructions provided by respective authors. Participant gender was coded as female $=1$ and male $=0$ and was included in preliminary analyses. Parent gender was coded as mother $=1$ and father $=0$ and included in the analyses so that families with same-sex parents could be coded correctly. Analyses were made using the Jamovi (2021; R Core Team, 2020; Ripley et al., 2018) statistical platform.

\section{Results}

\section{Descriptive Statistics and Preliminary Analyses}

Paired sample $t$-tests revealed that participants' average rate of answering the middle-sized target increased from the congruent control trials $(M=12.2 \%$; $S D=18.4 \%$; CI $[7.5 \%$ to $17 \%]$ ) to the incongruent trials $(M=25.7 \% ; S D=32.9 \% ; 95 \%$ CI $17.2 \%$; $34.1 \%]), t(54)=-2.46, d=1.16, p=0.017$, indicating that peer models significantly affected participants' answering, eliciting conformity at the group level. Overall, 26 out of the 55 participants never conformed, 11 conformed consistently (seven or eight of the eight trials), and 20 conformed intermittently (ranging from two to six out of the eight trials).

Interrater agreements (Table 1) of parental styles were fair or moderate for permissive and authoritarian factors. These two factors were mean-scored for each parent using self-rating and the rating given by the other parent. The interrater agreement for the authoritative factor was slight and in addition, no significant zero-order correlations were found between authoritative ratings and participants' behavioral measures.
Because of this unreliability in the measure, the authoritative factor was excluded from further analyses. Even though we only predicted an effect for authoritarian parenting, we included permissive parenting as an exploratory variable.

One participant was excluded from the anonymous sharing game due to parental interference. Out of the remaining 54 participants, 39 (72\%) did not donate any marbles, 11 (20\%) donated between 1 and 5 marbles, and $4(7 \%)$ donated all ten of their marbles. The majority of participants $(48 ; 87 \%)$ picked up all the spilled paper clips indicating a potential ceiling effect.

We found no effects of participant gender on behavioral outcomes (conformity $p=0.64$, anonymous sharing $p=0.21$, two-sided independent $t$-tests; or obedience $O R=0.96, p=1.00$, Fisher's exact test) nor differences in parenting styles (father authoritarian $p=0.82$, mother authoritarian $p=0.97$, father permissive $p=0.35$, mother permissive $p=0.84$; twosided independent $t$-tests). Participant gender was therefore not included in further analyses. A correlation matrix including all variables is shown in Table 2.

\section{Main Analyses}

Do children's obedience, anonymous sharing, and their parents' parental style relate to conformity? An linear regression model (Table 3 ), with conformity as dependent variable and maternal and paternal permissive and authoritarian styles, together with measures of obedience and anonymous sharing as predictors $\left(F(6,41)=3.61, p=0.006\right.$, adjusted $\left.R^{2}=0.25\right)$ showed that fathers' authoritarian style and children's own anonymous sharing both predict children's conformity. We replicated this regression using mothers' and fathers' ratings of themselves and the other parent separately, both of which yielded comparable results. 
Table 2

Matrix of Spearman's Rank Correlation Coefficients of Included Variables

\begin{tabular}{|c|c|c|c|c|c|c|}
\hline & 1 & 2 & 3 & 4 & 5 & 6 \\
\hline \multicolumn{7}{|l|}{ 1. Conformity } \\
\hline 2. Age & -0.03 & & & & & \\
\hline 3. Gender & 0.12 & 0.14 & & & & \\
\hline 4. Obedience & 0.07 & 0.08 & -0.01 & & & \\
\hline 5. Anonymous sharing & $0.32^{*}$ & -0.20 & -0.07 & 0.24 & & \\
\hline 6. Mothers' Authoritarian parenting & 0.20 & 0.09 & 0.01 & -0.13 & 0.01 & \\
\hline 7. Fathers' Authoritarian parenting & $0.35^{* *}$ & 0.10 & 0.14 & 0.01 & -0.19 & $0.67^{* * *}$ \\
\hline
\end{tabular}

Table 3

A Linear Regression Model with Conformity (0-1) as Dependent Variable, and Parental Ratings of Own and Other Parent's Authoritarian and Permissive Parental Styles, and Measures of Children's Obedience and Anonymous Sharing as Predictors

\begin{tabular}{lcccc}
\hline & $b^{*}$ & Std. Error & $t$ & $p$ \\
\hline Intercept & -0.89 & 0.34 & -2.62 & 0.01 \\
Maternal Authoritarian style & -0.31 & 0.19 & -1.66 & 0.10 \\
Paternal Authoritarian style & 0.82 & 0.22 & 3.72 & $<0.001$ \\
Maternal Permissive style & -0.21 & 0.18 & -1.15 & 0.26 \\
Paternal Permissive style & 0.37 & 0.19 & 1.89 & 0.07 \\
Obedience & -0.01 & 0.11 & -0.11 & 0.91 \\
Anonymous sharing & 0.04 & 0.02 & 2.44 & 0.02 \\
\hline
\end{tabular}

Note: ${ }^{*} b$ represents unstandardized regression weights.

Note that we here deviated from our preregistration in which we planned to use a mixed effects regression model, as linear regression yielded similar results and is simpler to present.

Do anonymous sharing and obedience relate to each other? A zero-order rank correlation between anonymous sharing and obedience was not significant $\left(r_{2}=0.24, p=0.09\right)$ nor was there a group-level difference in number of shared marbles between participants coded as obedient and non-obedient $(U=112, p=0.09$ ). Thus, while our data does not support a link between anonymous sharing and obedience, the ceiling effect of our obedience measure signals that the absence of statistical significance should be interpreted cautiously.

Does parental style relate to children's anonymous sharing and obedience? For these additional exploratory analysis, an ordinal logistic regression model with anonymous sharing as dependent variable and maternal and paternal authoritarian and permissive styles as predictors was not significant, $\left(\chi^{2}(4)=9.30 ; p=0.054\right)$. A binomial logistic regression model with obedience as dependent variable was not significant either $\left(\chi^{2}(4)=0.61 ; p=0.96\right)$. This suggests that parental style is not predictive of obedience or anonymous sharing. Main analyses and correlational data can be found at https://osf.io/ tn436/.

\section{Discussion}

Conformity is ubiquitous in humans and is an important part of our social lives. Yet, we conform to different extents and for different reasons, and why some have higher propensities to conform is poorly understood. To understand this variability better we therefore assessed 3.5-year-olds' propensity to conform to peers in order to examine how conformity relates to anonymous sharing behavior, obedience, and measures of parental style. Our results show that children's conformity is associated with authoritarian parental style, particularly that of male parents, and the child's own anonymous sharing behavior. These findings suggest that children's conformity to peers is associated with two independent factors - the psychosocial environment as affected by fathers' parenting style and a second factor encompassing social behavior which we discuss below.

Authoritarian parenting is primarily characterized by placing high demands on the child while at the same time not being sensitive to, or acknowledging, the child's own will, needs, or emotions (Baumrind, 1968). Authoritarian parenting thus entails less nurturing, patience, and willingness to let children democratically participate in the family, and has been argued to inherently encourage conformist behavior (Berger, 2014). However, this has not been shown empirically until now. What we believe is key to the current association with conformity is first that authoritarian parenting involves less trust when letting children make their own choices; authoritarian parents most often make decisions for their children. Second, authoritarian parenting also to some extent entails downplaying the child by stating, e.g., "how many times do I have to tell you?" and being more prone to answer the child's questions with "because I said so", rather than being responsive to the child's reason for their behavior or their inquiries. We argue that these parenting behaviors may be reflected in children of more authoritarian parents being unfamil- 
iar or uncomfortable making their own decisions and thus less willing to deviate from majority opinion. Interestingly, only fathers' authoritarian parenting style was predictive of children's conformity and we offer two tentative explanations for this difference. Firstly, authoritarian parenting scores were generally low in our sample, and lower for mothers than fathers. This may, for multiple reasons, have influenced or concealed a maternal effect. However, given the moderate inter-rater reliability scores and strong correlations between parental scores, this is not the most plausible explanation. Secondly, differential effects of fathers' and mothers' authoritarian style have previously been observed in other social behaviors of preschoolers (Carapito et al., 2018). A more probable explanation is, thus, that effects of parents' authoritarian parenting is exerted differently between fathers and mothers. However, future studies should explore more deeply how the authoritarian parental style promotes conformist behavior, incorporating a gender perspective.

Our results also show a relation between conformity and anonymous sharing behavior. We offer two tentative explanations for the connection between these behaviors, both of which draw from common social factors such as a temperamental or a personality trait. First, anonymous sharing can be predicted by parental ratings of their children's honesty-humility from the HEXACO-model of personality (Allgaier et al., 2020). The honesty-humility axis encapsulates children's greed avoidance (relevant for anonymous sharing) and modesty (relevant for conformity). We presume highly modest children would be more likely to conform, not wanting to present themselves as being more able than their peers, and similarly not wanting to have more material goods than their peers, which would explain the sharing result. A second alternative is that both behaviors may be prompted by an objective of social group cohesiveness by showing that they are similar to the peers (conformity) and avoiding that other peers are left out or victimized (anonymous sharing). This reasoning lends support to conformity being an act of affiliation, as proposed in the social alignment theory (ShamayTsoory et al., 2019). Thus, both modesty and the cohesiveness motives could underlie the relationship between conformity and sharing.

While we did not find any relations between conformity and obedience, or obedience and parental style, it is possible that this is due to low variability in our measure. It is also possible that obedience would correlate with children's conformity to adults, which we did not assess in this study. In addition, the obedience task could have elicited helping behavior, despite our attempts to differentiate it from situations that elicit helping, for example by having the experimenter give a direct order to participants despite being capable of completing the task himself. The vast majority of children picked up all the paperclips $(87 \%)$ and the rest picked up none. We were not able to code for additional data, such as latency or reluctance by qualitative measures of children's facial expressions, since the sessions were not recorded. It is possible that with a more sensitive measure of obedience, potential relationships between these variables could have been found.

We also did not find a relationship between anonymous sharing and parental style. In combination with the model showing that both authoritarian parental style and anonymous sharing contribute to predicting conformity propensity, this suggests that there are likely two separate individual difference contributions that were uncovered in the current study, rather than one factor that underlies both the parental style and the anonymous sharing effects.

Both parents rated their own parental style, as well as the other parent's parental style, which allowed us to confirm inter-rater consistencies. Correlations between self-rated and other-parent-rated qualities for permissive and authoritarian dimensions were moderate. The ratings of authoritative style, however, did not correlate between parents' self-ratings and their ratings of each other. Notably, this there were also a ceiling effect in this measure. Why this occurred is interesting because authoritative parental style, unlike the authoritarian and permissive dimensions, consists of parenting qualities that are seen as positive and favorable in the culture where the study was conducted (Olivari et al., 2015). Hence, the poor inter-rater correlations and ceiling effect can possibly be attributed to social desirability biases and has implications for the criterion validity of the authoritative dimension of the PSDQ.

The current study is the first to show that authoritarian parental style is associated with children's conformity. This finding is important because it highlights a specific way in which the behaviors and attitudes of primary caregivers affect their children's social behavior with peers. Our interpretation is that authoritarian parents, who less sensitively respond to children's behaviors and inquiries, diminish children's willingness to deviate from norms or their inclination to form independent opinions. We are also the first to show a link between conformity and anony- 
mous sharing, highlighting both a tentative common connection with social dispositions as well as a topic for future inquiry.

\section{Acknowledgments}

This research was supported by the European Research Council (ERC StG CACTUS 312292) and the Swedish Research Council (2014-1156). The authors wish to thank all participating children and their parents.

\section{References}

Asch, S. E. (1956). Studies of independence and conformity: I. A minority of one against a unanimous majority. Psychological Monographs: General and Applied, 70(9), 1. https:// doi:10.1037/h0093718

Allgaier, K., Ścigała, K. A., Trautwein, U., Hilbig, B. E., \& Zettler, I. (2020). Honesty-humility and dictator and ultimatum gamegiving in children. Journal of Research in Personality, 85, 103907. https://doi:10.1016/j.jrp.2019.103907

Baars, J., \& Scheepers, P. (1993). Theoretical and methodological foundations of the authoritarian personality. Journal of the History of the Behavioral Sciences, 29(4), 345-353. https://doi:10.1002/1520-6696(199310)29:4<345::aid-jhbs 2300290405>3.0.co;2-1

Baumrind, D. (1968). Authoritarian vs. authoritative parental control. Adolescence, 3(11), 255-272.

Berenda, R. W. (1950). The influence of the group on the judgments of children. King's Crown Press.

Berger, K. (2014). The developing person through the lifespan. Worth Publishers.

Bond, R., \& Smith, P. B. (1996). Culture and conformity: A meta-analysis of studies using Asch's (1952b, 1956) line judgment task. Psychological Bulletin, 119(1), 111-137. https:// doi:10.1037/0033-2909.119.1.111

Carapito, E., Ribeiro, M. T., Pereira, A. I., \& Roberto, M. S. (2018). Parenting stress and preschoolers' socio-emotional adjustment: The mediating role of parenting styles in parent-child dyads. Journal of Family Studies, 26(4), 594-610. https:// doi:10.1080/13229400.2018.1442737

Cirelli, L. K. (2018). How interpersonal synchrony facilitates early prosocial behavior. Current Opinion in Psychology, 20, 35-39. https://doi:10.1016/j.copsyc.2017.08.009

Clark, L. A., Kochanska, G., \& Ready, R. (2000). Mothers' personality and its interaction with child temperament as predictors of parenting behavior. Journal of Personality and Social Psychology, 79(2), 274-285. https://doi:10.1037/0022-3514.79 .2 .274

Clegg, J. M., Wen, N., \& Legare, C. H. (2017). Is non-conformity WEIRD? Cultural variation in adults' beliefs about children's competency and conformity. Journal of Experimental Psychology: General, 146(3), 428-441.

Cordonier, L., Nettles, T., \& Rochat, P. (2017). Strong and strategic conformity understanding by 3 -and 5-year-old children. British Journal of Developmental Psychology, 36(3), 438-451. https:// doi:10.1111/bjdp.12229
Corriveau, K. H., \& Harris, P. L. (2010). Preschoolers (sometimes) defer to the majority in making simple perceptual judgments. Developmental Psychology, 46(2), 437-445. https:// doi: $10.1037 / \mathrm{a} 0017553$

Eagly, A. H., \& Wood, W. (1982). Inferred sex differences in status as a determinant of gender stereotypes about social influence. Journal of Personality and Social Psychology, 43(5), 915-928. https://doi:10.1037/0022-3514.43.5.915

Engelmann, J. M., Herrmann, E., Rapp, D. J., \& Tomasello, M. (2016). Young children (sometimes) do the right thing even when their peers do not. Cognitive Development, 39, 86-92. https://doi:10.1016/j.cogdev.2016.04.004

Flynn, E., Turner, C., \& Giraldeau, L. A. (2018). Follow (or don't follow) the crowd: Young children conformity is influenced by norm domain and age. Journal of Experimental Child Psychology, 167, 222-233. https://doi:10.1016/j.jecp.2017.10. 014

Gagnon, S. G., Huelsman, T. J., Reichard, A. E., Kidder-Ashley, P., Griggs, M. S., Struby, J., \& Bollinger, J. (2014). Help me play! Parental behaviors, child temperament, and preschool peer play. Journal of Child and Family Studies, 23(5), 872-884. https://doi:10.1007/s10826-013-9743-0

Guidetti, M., Carraro, L., \& Castelli, L. (2017). An exploration of the differential effects of parents' authoritarianism dimensions on pre-school children's epistemic, existential, and relational needs. Frontiers in Psychology, 7, 2079. https://doi:10.3389/ fpsyg.2016.02079

Gummerum, M., Hanoch, Y., Keller, M., Parsons, K., \& Hummel, A. (2010). Preschoolers' allocations in the dictator game: The role of moral emotions. Journal of Economic Psychology, 31(1), 25-34. https://doi:10.1016/j.joep.2009.09.002

Haun, D., \& Tomasello, M. (2011). Conformity to peer pressure in preschool children. Child Development, 82(6), 1759-1767. https://doi:10.1111/j.1467-8624.2011.01666.x

Haun, D. B., Rekers, Y., \& Tomasello, M. (2012). Majority-biased transmission in chimpanzees and human children, but not orangutans. Current Biology, 22(8), 727-731. https://doi:10. 1016/j.cub.2012.03.006

Hellmer, K., Stenberg, G., \& Fawcett, C. (2018). Preschoolers' conformity (and its motivation) is linked to own and parents' personalities. British Journal of Developmental Psychology, 36(4), 573-588. https://doi:10.1111/bjdp.12243

Hellmer, K., Stenberg, G., \& Fawcett, C. (2021). Preschoolers' extroversion influences their propensity and motivation to conform to peer testimony [Manuscript submitted for publication]. Department of Psychology, Uppsala University.

The jamovi project (2021). jamovi (Version 1.6) [Computer Software]. Retrieved from https://www.jamovi.org

Juteau, A. L., Cossette, I., Millette, M. P., \& Brosseau-Liard, P. (2019). Individual differences in children's preference to learn from a confident informant. Frontiers in Psychology, 10, 2006. https://doi:10.3389/fpsyg.2019.02006

Landauer, T. K., Carlsmith, J. M., \& Lepper, M. (1970). Experimental analysis of the factors determining obedience of four-year-old children to adult females. Child Development, 601-611. https://doi:10.2307/1127210

Klucharev, V., Hytönen, K., Rijpkema, M., Smidts, A., \& Fernández, G. (2009). Reinforcement learning signal predicts social conformity. Neuron, 61(1), 140-151. https:// doi:10.1016/j.neuron.2008.11.027

Ma, L., \& Ganea, P. A. (2010). Dealing with conflicting information: Young children's reliance on what they see versus what 
they are told. Developmental Science, 13(1), 151-160. https:// doi:10.1111/j.1467-7687.2009.00878.x

Manuel, L. (2006). Relationship of personal authoritarianism with parenting styles. Psychological Reports, 98(1), 193-198. https://doi:10.2466/pr0.98.1.193-198

McGuigan, N., \& Robertson, S. (2015). The influence of peers on the tendency of 3-and 4-year-old children to over-imitate. Journal of Experimental Child Psychology, 136, 42-54. https:// doi:10.1016/j.jecp.2015.03.004

McGuigan, N., \& Stevenson, A. (2016). Does the age and familiarity of the informant group influence the tendency of 3-and 4-year-old children to conform? The Journal of Genetic Psychology, 177(4), 122-130. https://doi:10.1080/00221325. 2016.1191424

McGuigan, N., \& Burgess, V. (2017). Is the tendency to conform influenced by the age of the majority? Journal of Experimental Child Psychology, 157, 49-65. https://doi:10.1016/j.jecp. 2016.12.007

Morgan, T. J., Laland, K. N., \& Harris, P. L. (2015). The development of adaptive conformity in young children: effects of uncertainty and consensus. Developmental Science, 18(4), 511-524. https://doi:10.1111/desc.12231

Olivari, M. G., Wahn, E. H., Maridaki-Kassotaki, K., Antonopoulou, K., \& Confalonieri, E. (2015). Adolescent perceptions of parenting styles in Sweden, Italy and Greece: An exploratory study. Europe's Journal of Psychology, 11(2), 244-258. https:// doi:10.5964/ejop.v11i2.887

Pastorelli, C., Lansford, J. E., Luengo Kanacri, B.P., Malone, P.S., Di Giunta, L., Bacchini, D., Silvia Bombi, A., Zelli, A., Miranda, M. C., Bornstein, M. H., Tapanya, S., Uribe Tirado, L. M., Alampay, L. P., Al-Hassan, S. M., Chang, L., Deater-Deckard, K., Dodge, K. A., Oburu, P., Skinner, A. T., \& Sorbring, E., (2016). Positive parenting and children's prosocial behavior in eight countries. Journal of Child Psychology and Psychiatry, 57(7), 824-834. https://doi:10.1111/jcpp. 12477

Paulus, M., Becker, E., Scheub, A., \& König, L. (2016). Preschool children's attachment security is associated with their sharing with others. Attachment \& Human Development, 18(1), 1-15. https://doi:10.1080/14616734.2015.1100208

Paulus, M., \& Leitherer, M. (2017). Preschoolers' social experiences and empathy-based responding relate to their fair resource allocation. Journal of Experimental Child Psychology, 161, 202-210. https://doi:10.1016/j.jecp.2017.03.005

Pinquart, M. (2017). Associations of parenting dimensions and styles with externalizing problems of children and adolescents: An updated meta-analysis. Developmental Psychology, 53(5), 873-932. https://doi:10.1037/dev0000295

Prinzie, P., Stams, G. J. J., Deković, M., Reijntjes, A. H., \& Belsky, J. (2009). The relations between parents' Big Five personality factors and parenting: A meta-analytic review. Journal of Personality and Social Psychology, 97(2), 351-362. https:// doi:10.1037/a0015823

R Core Team (2020). R: A Language and environment for statistical computing. (Version 4.0) [Computer software]. Retrieved from https://cran.r-project.org

Reifen Tagar, M., Federico, C. M., Lyons, K. E., Ludeke, S., \& Koenig, M. A. (2014). Heralding the authoritarian? Orientation toward authority in early childhood. Psychological Science, 25(4), 883-892. https://doi:10.1177/0956797613516470

Ripley, B., Venables W., Bates, D. M., Hornik, K., Gebhardt, A., \& Firth, D. (2018). MASS: Support functions and dDatasets for Venables and Ripley's MASS. [R package]. Retrieved from https://cran.r-project.org/package=MASS.

Robinson, C. C., Mandleco, B., Olsen, S. F., \& Hart, C. H. (1995). Authoritative, authoritarian, and permissive parenting practices: Development of a new measure. Psychological Reports, 77(3), 819-830. https://doi:10.2466/pr0.1995.77.3.819

Roopnarine, J. L., Krishnakumar, A., Metindogan, A., \& Evans, M. (2006). Links between parenting styles, parent-child academic interaction, parent-school interaction, and early academic skills and social behaviors in young children of Englishspeaking Caribbean immigrants. Early Childhood Research Quarterly, 21(2), 238-252. https://doi:10.1016/j.ecresq.2006. 04.007

Schillaci, R. S., \& Kelemen, D. (2014). Children's conformity when acquiring novel conventions: The case of artifacts. Journal of Cognition and Development, 15(4), 569-583. https:// doi: 10.1080/15248372.2013.784973

Sebastián-Enesco, C, Guerrero, S, Enesco, I. (2020). What makes children defy their peers? Chinese and Spanish preschoolers' decisions to trust (or not) peer consensus. Social Development, 29, 494- 508. https://doi:10.1111/sode.12416

Shamay-Tsoory, S. G., Saporta, N., Marton-Alper, I. Z., \& Gvirts, H. Z. (2019). Herding brains: A core neural mechanism for social alignment. Trends in Cognitive Sciences, 23(3), 174-186. https://doi:10.1016/j.tics.2019.01.002

Stenner, K. (2009). Three kinds of “conservatism”. Psychological Inquiry, 20(2-3), 142-159. https://doi:10.1080/104784009030 28615

Takagishi, H., Kameshima, S., Schug, J., Koizumi, M., \& Yamagishi, T. (2010). Theory of mind enhances preference for fairness. Journal of Experimental Child Psychology, 105(1), 130-137. https://doi:10.1016/j.jecp.2009.09.005

Tavassolie, T., Dudding, S., Madigan, A. L., Thorvardarson, E., \& Winsler, A. (2016). Differences in perceived parenting style between mothers and fathers: implications for child outcomes and marital conflict. Journal of Child and Family Studies, 25(6), 2055-2068. https://doi:10.1007/s10826-016-0376-y

Vaughan, G. M. \& White, K. D., (1964). The trans-situational aspect of conforming behavior. Journal of Personality, 32(3), 335-354. https://doi:10.1111/j.1467-6494.1964.tb01344.x

Walker, M. B., \& Andrade, M. G. (1996). Conformity in the Asch task as a function of age. The Journal of Social Psychology, 136(3), 367-372. https://doi:10.1080/00224545.1996.9714 014

Warneken, F. (2015). Precocious prosociality: Why do young children help? Child Development Perspectives, 9(1), 1-6. https:// doi:10.1111/cdep.12101

Whiten, A., \& Flynn, E. (2010). The transmission and evolution of experimental microcultures in groups of young children. Developmental Psychology, 46(6), 1694. https://doi:10.1037/ a0020786

Zadeh, S. Y., Jenkins, J., \& Pepler, D. (2010). A transactional analysis of maternal negativity and child externalizing behavior. International Journal of Behavioral Development, 34(3), 218-228. https://doi:10.1177/0165025409350953

\section{Bio Sketches}

Kahl Hellmer, Ph.D., M.Sc., is a Researcher at Uppsala Child and Baby Lab, Department of Psychology, 
Uppsala University. Kahl's research interests include the interplay of psychological and psychosocial factors of behaviors and beliefs, primarily in children (e.g., conformity and identity development) but also in adults (e.g., science denial and sexism).

Gunilla Stenberg, Ph.D. and licensed psychologist, is a Professor at Uppsala Child and Baby Lab, Department of Psychology, Uppsala University. Gunilla's research topics primarily include infant social referencing and imitation.
Christine Fawcett, Ph.D., is an Associate Professor at Uppsala Child and Baby Lab, Department of Psychology, Uppsala University. Christine's research focuses on children's social interactions (e.g., how children signal and interpret intentions; behavioral and physiological alignment), the developing gender identity, and children's attitudes about social groups. 